\title{
¿Pupilas isocóricas?
}

\section{Isocoric pupils?}

\author{
Alfredo Pinzón • Bogotá, D.C. (Colombia)
}

\section{¿Pupilas isocóricas?}

Es frecuente encontrar las expresiones compuestas pupilas isocóricas o isocoria pupilar en la descripción del examen físico ocular y/o neurológico. Pese a que dichos términos se encuentran descritos en algunos diccionarios y textos médicos, se debe rechazar su uso por considerarse redundante, puesto que el griego kór $(\overline{\boldsymbol{e}})$ significa "pupila" (este del latín pūpilla: "niñita").

En tal sentido, para evitar estos pleonasmos es recomendable utilizar el término simple:

Isocoria: (iso- gr. «igual» + kór(e) gr. «pupila» + -íā gr.):

1. s.f. Igualdad de tamaño entre ambas pupilas.

2. s.f. Pupilas del mismo tamaño.

Los siguientes son ejemplos del uso correcto de este término:

- Isocoria reactiva a la luz y la acomodación

- Isocoria normorreactiva

- Isocoria normorrefléxica

\section{Fuentes:}

- Real Academia Nacional de Medicina. Diccionario de Términos Médicos. Editorial Médica Panamericana. 2012

- Facultad de Medicina Universidad de Navarra. Diccionario Espasa de Medicina. Espasa Calpe S.A. 2000

- Diccionario de la Real Academia Española de la Lengua, disponible en: www.rae.es

\footnotetext{
* Envíe sus inquietudes, sugerencias o comentarios a: actmedco@etb.net.co - alfredo.pinzon@hus.org.co Dr. Alfredo Pinzón Junca: Especialista en Medicina Interna y Psicoanálisis. Hospital Universitario de La Samaritana y Hospital Simón Bolívar. Coordinador del Consejo de Acreditación y Recertificación de la ACMI ${ }^{\circledast}$. Bogotá, D.C. (Colombia). E-mail: alfredo.pinzon@hus.org.co

Recibido: 30/XI/2014 Aceptado: 2/XII/2014
} 